J. Lake Sci.(湖泊科学), 2017, 29(1): 127-134

DOI 10. 18307/2017. 0114

(c) 2017 by Journal of Lake Sciences

\title{
京蒙沙源区水库大气磷干、湿沉降污染特征"
}

\author{
卢俊平, 马太玲 ${ }^{* *}$, 刘廷焦, 张晓晶, 于淑玉 \\ ( 内蒙古农业大学水利与土木建筑工程学院, 呼和浩特 010018)
}

\begin{abstract}
摘 要: 为阐明典型沙源区水库大气磷干、湿沉降的污染特征及其对水域磷素污染的贡献,为水库富营养化治理提供科 学依据, 以京蒙沙源区大河口水库库区为研究区, 于 2014 年沿水库岸边布设 12 个大气沉降监测站点, 采集干、湿沉降样 品, 测定干、湿沉降中总磷 (TP) 浓度, 计算全年各月大气 TP 干、湿沉降通量和年人库 TP 污染负荷量. 结果表明: 研究区 大气干、湿沉降季节差异显著, 全年各月 $\mathrm{TP}$ 干沉降通量变化范围为 $4.89 \sim 35.76 \mathrm{~kg} /\left(\mathrm{km}^{2} \cdot\right.$ 月 ), 主要集中在春季 4 月和 秋季 10 月. 最大 TP 干沉降通量出现在春季风沙最为严重的 4 月; 湿沉降主要集中在夏季 (6-8 月), 最大 TP 湿沉降通量 出现在降雨量最大的 8 月, 为 $28.88 \mathrm{~kg} /\left(\mathrm{km}^{2}\right.$ - 月 ), 且 TP 湿沉降通量与降雨量呈显著正相关. 2014 年大气 TP 沉降人库 污染负荷量为 $0.719 \mathrm{t}$, 占同期滦河和吐力根河两条河流人库 TP 污染负荷比率为 $51.17 \%$, 成为影响和限制大河口水库磷 营养盐水平的重要源项之一.
\end{abstract}

关键词: 京蒙沙源区; 大河口水库; 总磷; 干沉降; 湿沉降

\section{Pollution characteristics of atmospheric dry and wet phosphorus deposition on a reservoir in sand source areas of Beijing-Inner Mongolia}

\author{
LU Junping, MA Tailing ** , LIU Tingxi, ZHANG Xiaojing \& YU Shuyu \\ (Water Conservancy and Civil Engineering College, Inner Mongolia Agricultural University, Hohhot 010018, P.R.China)
}

\begin{abstract}
To illustrate pollution characteristics of atmospheric dry and wet phosphorus deposition of reservoir in the typical sand source area and their contribution to the water phosphorus pollution in order to provide scientific basis for governance of the reservoir eutrophication, we set 12 atmospheric precipitation monitoring sites along the reservoir shore in 2014 in Dahekou Reservoir area in sand source areas of Beijing-Inner Mongolia, and collected dry and wet sedimentation samples to determine concentration of total phosphorus (TP) in dry and wet subsidence and to calculate the yearly and monthly fluxes and the annual storage of TP loading. The results showed that atmospheric TP dry and wet deposition had significantly seasonal differences in the study area. The TP dry deposition flux ranged between $4.89-35.76 \mathrm{~kg} /\left(\mathrm{km}^{2} \cdot \mathrm{month}\right)$ in the year, and was mainly concentrated in the spring (April) and autumn (October). The maximum of TP dry deposition flux appeared in the most serious sandstorm month of spring (April). Wet deposition was mainly concentrated in the summer (June to August). The maximum of TP wet subsidence flux appeared in the largest rainfall month (August), and its value was $28.88 \mathrm{~kg} /\left(\mathrm{km}^{2} \cdot \mathrm{month}\right)$. The TP wet subsidence flux was significantly positively related with rainfall. Atmospheric pollutant load of TP subsidence storage was $0.719 \mathrm{t}$ in 2014, and the ratio of TP pollution load of both Luan River and Tuligen River storage was $51.17 \%$ in the same period. They have become one of the important source term of influencing and restricting the phosphorus nutrient levels in Dahekou Reservoir.
\end{abstract}

Keywords: Sand source areas of Beijing-Inner Mongolia; Dahekou Reservoir; total phosphorus; dry deposition; wet deposition

随着农业和工业的快速发展, 全球水库 (湖泊) 环境污染急剧扩大, 国内外学者对磷营养盐的来源展开 了深人研究, 发现大气磷沉降与湖泊、海洋等水域富营养化有着密切的关系 ${ }^{[1-6]}$. Tamatamah 等 ${ }^{[7]}$ 对东非维多 利亚湖的研究表明, 湖泊中溶解态反应性磷 (SRP) 的大气湿沉降率为 $40 \sim 60 \mathrm{~kg} /\left(\mathrm{km}^{2} \cdot \mathrm{d}\right)$. Markaki 等 ${ }^{[8]}$ 对

* 国家自然科学基金项目 (51369020,51669023) 和内蒙古自然科学基金项目(2012MS0614) 联合资助. 2016-03-14 收稿; 2016-05-14 收修改稿. 卢俊平(1977 ), 男,副教授; E-mail: ljpcau@ 163.com.

** 通信作者; E-mail: nmg-hippo@163.com. 
地中海东部的利万特海调查发现, 大气降尘中溶解性无机磷 (DIP) 占海洋总磷负荷的 $38 \%$. Vicars 等 ${ }^{[9]}$ 对 Sierra Nevada 湖的研究显示, 水体相对较高的磷浓度及较低的 N/P 与大气沉降有关, 大气沉降是湖泊水体 磷的主要来源, 与湖泊富营养化有着密切的关系. 近年来, 我国学者在大气磷沉降对水体富营养化的贡献方 面做了大量研究 ${ }^{[10-13]}$, 研究区域主要集中于农田和长江口水域、九龙江流域、珠三角地区近海海域及内陆太 湖地区, 研究内容包括大气降尘磷来源、化学形态特征、沉降过程等, 并取得了显著进展. 对北方内陆水库 (湖泊) 水域大气磷沉降影响水生态环境的研究成果甚少, 尤其关于因大气风沙作用引起水体磷污染的文献 资料至今鲜见.

本文的研究区为内蒙古锡林郭勒盟多伦县大河口水库. 大河口水库 $\left(42^{\circ} 13^{\prime} 19.17^{\prime \prime} \mathrm{N}, 116^{\circ} 38^{\prime} 4.00^{\prime \prime} \mathrm{E}\right)$ 于 1995 年 8 月建成, 位于锡林郭勒盟浑善达克沙地京蒙沙源区腹地、多伦县境内的滦河干流上, 水域面积 $17.262 \mathrm{~km}^{2}$, 主要受吐力根河和滦河人库地表径流补给, 是一座以供水发电为主、兼具农业灌溉和水产养殖 等功能的中型水库 ${ }^{[14]}$. 受北方季风气候和干旱少雨特征的显著影响, 沙源区风沙输移量大, 年均 8 级以上大 风日数达 80 余天,扬沙和沙尘暴天气频繁出现. 且风沙污染来源广泛,包括半流动沙丘、撂荒地、荒草地、春 秋冬季裸露的耕地, 尤其是沙源区内广泛分布的干涸盐湖, 其湖底蓄积的大量含磷营养盐的污染物质随风 飘散, 极可能成为水库大气磷沉降的重要潜在来源 ${ }^{[15]}$.

为了正确认识我国北方地区大气磷沉降对沙源区水库污染贡献和水体富营养化影响, 对研究区水库的 大气磷干、湿沉降污染特征展开研究. 于 2014 年 1-12 月环大河口水库周边布置 12 个大气干、湿沉降观测 站点, 进行为期 1 年的干、湿沉降样本采集和室内分析测试工作, 计算沙源区大河口水库大气磷干、湿沉降 通量和人库污染负荷率, 分析讨论大气磷干、湿沉降污染特征及其对水库富营养化的贡献和影响.

\section{1 材料与方法}

\section{1 采样点的布设}

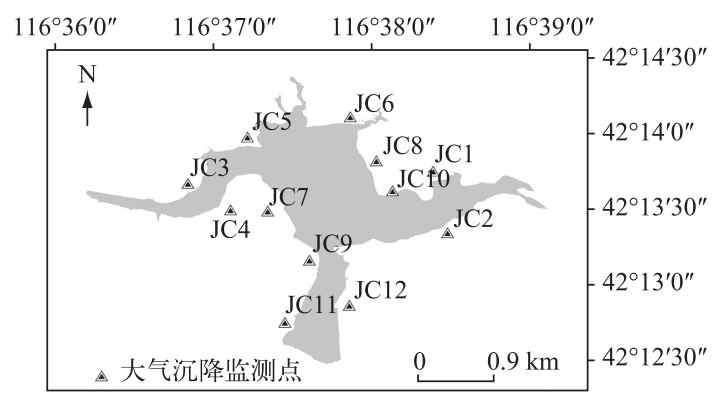

图 1 大河口水库大气沉降监测点布设方案

Fig. 1 Layout scheme of atmospheric deposition monitoring sites in the Dahekou Reservoir
为了能更准确地反映大气磷沉降对水库的影 响, 监测点设置的原则遵循距离水库岸边最近, 采 集器不易损坏, 避开周边高地、大树或建筑的遮挡 和局部污染源, 兼顾主导风向的原则, 在环大河口 水库周边布设 12 个大气干、湿沉降监测站点, 分别 编号为 JC1 JC12 (图 1). 每个监测站点放置 3 个 大气沉降采集器.

\section{2 样品收集与测试}

大气总磷 $(\mathrm{TP})$ 干、湿沉降物采集参照《大气降 水样品的采集与保存标准》( GB/T 153580.2$1992)$ 和《环境空气质量自动监测技术规范》( HJ/T 193-2005) 进行 ${ }^{[16]}$. 采集器为内径 $\varnothing 150 \mathrm{~mm}$ 的标 准玻璃缸, 置于高出地面 $1.5 \mathrm{~m}$ 处的铁架中, 采集

器口安设不锈钢丝网罩以防昆虫、鸟粪掉人影响样品总磷测定结果.

干沉降采集: 将大气干沉降采集器放置在监测站点采样架上, 收集大气干沉降 (每次取样后在采集器内 加人少量乙二醇水溶液, 防止冰冻和抑制微生物和藻类生长, 尽量减免微生物降解作用对样品 TP 浓度的影 响). 降水前将采样器用盖密封, 降水结束后立即打开. 每月最后一天收集采集器中的样品.

湿沉降采集: 在每次降水开始前约 5 10 min, 在大气沉降监测站点采样架上放置湿沉降采集器, 降水结 束后从采集器中收集降雨或降雪样品, 并将湿沉降采集器收回. 每月记录湿沉降采集次数和降水量. 降水量 采用翻斗式雨量计自动记录.

每月将干、湿降尘样品带回实验室测定滤液 TP 浓度, 同时记录大气沉降采集器内液体体积. 大气干、湿 沉降 $\mathrm{TP}$ 浓度分析参照 《水和废水监测分析方法》(第 4 版 ${ }^{[17]}$ 中的 $\mathrm{A}$ 类方法进行, 测定方法为碱性过硫酸钾 消解紫外分光光度法. 


\section{3 研究方法}

根据 2014 年全年各月大气干、湿沉降监测点收集的干、湿沉降液体体积及其样品中 TP 浓度, 结合各站 点大气干、湿沉降采集器个数 (每站点 3 个) 和采集器面积, 分别用公式 (1) 和公式 (2) 计算 2014 年全年各 月大气 TP 干、湿沉降通量. 此外, 在滦河、吐力根河人库口分别设置水质监测断面 $\mathrm{L}$ 和 $\mathrm{T}$, 每月监测水体 $\mathrm{TP}$ 浓度,结合大河口水库管理站提供的两河人库径流资料,按公式(3)估算河流人库 TP 污染负荷量.

干沉降通量计算公式为:

$$
F_{\mathrm{d}}=\frac{k_{\mathrm{d}} \cdot C \cdot V}{f \cdot S}=\frac{56.59 C \cdot V}{f}
$$

式中, $F_{\mathrm{d}}$ 为大气 TP 月干沉降通量 $\left(\mathrm{kg} /\left(\mathrm{km}^{2} \cdot\right.\right.$ 月 $\left.)\right) ; k_{\mathrm{d}}$ 为换算系数, $k_{\mathrm{d}}=10^{-3} ; C$ 为收集液中的 TP 质量浓度 $(\mathrm{mg} / \mathrm{L}) ; V$ 为收集液体积 $(\mathrm{L}) ; S$ 为采集器面积, 为 $0.018 \mathrm{~m}^{2} ; k_{\mathrm{d}} / S=56.59 \times 10^{-3} \mathrm{~m}^{-2} ; f$ 为采样时间系数 $\left(\mathrm{d}^{-1}\right)$, $f=t / 24 ; t$ 为样品收集的时间.

湿沉降通量计算公式为:

$$
F_{\mathrm{w}}=\sum_{i=1}^{n} \frac{k_{\mathrm{w}} \cdot C_{i} \cdot V_{i}}{S}=\sum_{i=1}^{n} k_{\mathrm{w}} \cdot C_{i} \cdot h
$$

式中, $F_{\mathrm{w}}$ 为大气 $\mathrm{TP}$ 月湿沉降通量 $\left(\mathrm{kg} /\left(\mathrm{km}^{2} \cdot\right.\right.$ 月 $\left.)\right) ; k_{\mathrm{w}}$ 为单位换算系数, $k_{\mathrm{w}}=10^{-3} ; C_{i}$ 为雨或雪水中 $\mathrm{TP}$ 质量 浓度 $(\mathrm{mg} / \mathrm{L}) ; V_{i}$ 为采集雨、雪水的体积 $(\mathrm{L}) ; S$ 为采集器面积, 为 $0.018 \mathrm{~m}^{2} ; h$ 为月降水量 $(\mathrm{mm}) ; n$ 为月降水 (雪) 次数.

河流径流人库 TP 负荷计算公式为:

$$
M=\rho_{i} \cdot Q_{i} \times 3600 \times 24 \times n_{i} \times 10^{-6}
$$

式中, $M$ 为每月河流人库 $\mathrm{TP}$ 负荷量 $(\mathrm{t}) ; \rho_{i}$ 为 $\mathrm{TP}$ 浓度 $(\mathrm{mg} / \mathrm{L}) ; Q_{i}$ 为月平均人库断面径流量 $\left(\mathrm{m}^{3} / \mathrm{s}\right) ; n_{i}$ 为每月 天数 $(\mathrm{d})$.

\section{2 结果与讨论}

\section{1 大气 TP干、湿沉降通量}

2014 年观测期内, 大河口水库 TP 总沉降通量变化范 围为 $6.32 \sim 42.80 \mathrm{~kg} /\left(\mathrm{km}^{2}\right.$. 月), 平均值为 $22.96 \mathrm{~kg} /\left(\mathrm{km}^{2}\right.$. 月). 与我国其他研究地区相比, 月平均 TP 沉降通量与我 国南部太湖 TP 沉降通量 $23.0 \mathrm{~kg} /\left(\mathrm{km}^{2}\right.$. 月) 基本接 近 $)^{[10]}$, 高于杭州北里湖 TP 沉降通量 $5.96 \mathrm{~kg} /\left(\mathrm{km}^{2}\right.$. 月) ${ }^{[18]} .2014$ 年全年各月 $\mathrm{TP}$ 干沉降通量变异系数为 0.60 ,湿沉降通量变异系数为 1.00 . 由此可见, TP 月干沉 降通量值年内各月相对变异小,而月湿沉降通量受年内各 月降雨分配极不均匀的影响,变异特征显著 (表 1 ).
表 1 大河口水库大气 $\mathrm{TP}$ 干、 湿沉降通量和总沉降通量统计结果

Tab.1 Atmospheric dry, wet and total deposition fluxes of phosphorus in Dahekou Reservoir area

\begin{tabular}{cccc}
\hline \multirow{2}{*}{ 统计量 } & \multicolumn{3}{c}{$\mathrm{TP}$ 沉降通量 $/\left(\mathrm{kg} /\left(\mathrm{km}^{2} \cdot\right.\right.$ 月 $\left.)\right)$} \\
\cline { 2 - 4 } & 干沉降 & 湿沉降 & 总沉降 \\
\hline 最小值 & 4.89 & 0.26 & 6.32 \\
最大值 & 35.75 & 28.88 & 42.80 \\
平均值 & 14.19 & 8.77 & 22.96 \\
标准差 & 8.51 & 8.81 & 10.58 \\
变异系数 & 0.60 & 1.00 & 0.46 \\
\hline
\end{tabular}

\section{2 大气 TP 月干、湿沉降通量的变化特征}

大气中的磷与氮不同, 主要以悬浮颗粒物的形式存在. 因此, 在过去的研究中, 大气磷的输人对生态系 统的影响与其他来源磷的输人相比就被忽略了, 且在研究磷循环时未考虑大气中的磷 ${ }^{[19-20]}$. 然而, 在磷来源 少的生态系统环境中,大气磷沉降扮演着十分重要的角色 ${ }^{[21]}$.

本研究根据 2014 年全年各月大气干、湿沉降监测站点收集的干、湿沉降液及其 TP 浓度,结合各站点采集 器个数( 每站点 3 个)、采集器面积和每月降水量, 计算 2014 年全年各月大河口水库大气 TP 干、湿沉降通量. 结果表明,2014 年 TP 月干沉降通量随时间变化曲线具有明显的季节特征, 表现为春、秋季 TP 月干沉降通量高 于冬、夏季. 全年 TP 干沉降通量随时间变化曲线也出现了两次峰值, 分别为 4 和 10 月, 尤其以 4 月 TP 干沉降 通量值最高, 为 $35.75 \mathrm{~kg} /\left(\mathrm{km}^{2} \cdot\right.$ 月), 是年平均 $\mathrm{TP}$ 干沉降通量 $14.19 \mathrm{~kg} /\left(\mathrm{km}^{2} \cdot\right.$ 月) 的 2.5 倍(图 2).

$\mathrm{TP}$ 干沉降通量随时间的变化与当地的气象特征 (风向、风速) 有关. 由图 3、4 可见,多伦县年主导风向为 WSW 风, 出现频率为 $12.8 \%$, 全年以 WSW 方向的风平均风速最大, 为 $5.0 \mathrm{~m} / \mathrm{s}$. 研究区地处内蒙古中东部, 地面 


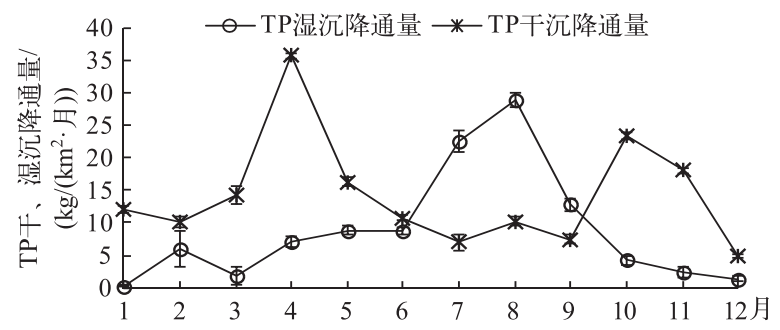

图 2 大河口水库大气 $\mathrm{TP}$ 干、湿沉降通量的月变化曲线

Fig.2 Monthly change curves of wet and dry deposition fluxes of atmospheric phosphorus in Dahekou Reservoir area

风的变化规律为: 冬、春季,东亚高空西风急流正位于内蒙古上空,当蒙古气旋发展时,内蒙古处在上下一致的 西风气流中,有利于高空动量下传,使低层的偏西风加大,这就造成该地区在冬、春季易出现大风天气;夏季由 于降水相对集中, 当锋面过境可伴有雷雨和大风天气, 瞬时风速较大, 但夏季平均风速是四季中最小的; 秋季 为冷暖气团的交替时期, 此时气团活动频繁, 因此风沙天气较多, 且温度较高, 有利于灰尘中有机质的矿化作 用,加之降水较少, 磷元素在灰尘中极易长时间积累, 形成较高的含量, 水库 WSW 方向的裸露沙地随风起尘, 经大气扩散输送至水库沉降, 而冬、夏季受降雪、降雨的影响, 大气中的灰尘受降雪和降雨的冲刷而吸附扬尘 中的营养盐离子, 从而不利于磷元素在灰尘中的积累,直接导致 TP 干沉降通量较低 ${ }^{[22]}$.

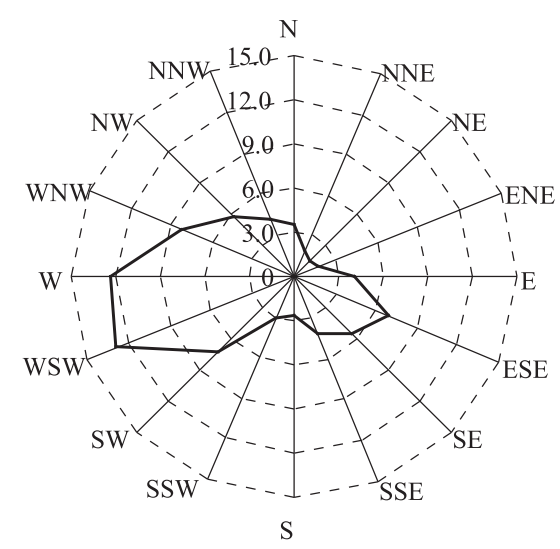

全年(静风的年出现频率为 $14.8 \%$ )

图 3 多伦县近 30 年全年风向频率玫瑰图

Fig. 3 The figure of annual wind frequency rose of Duolun County in recent 30 years

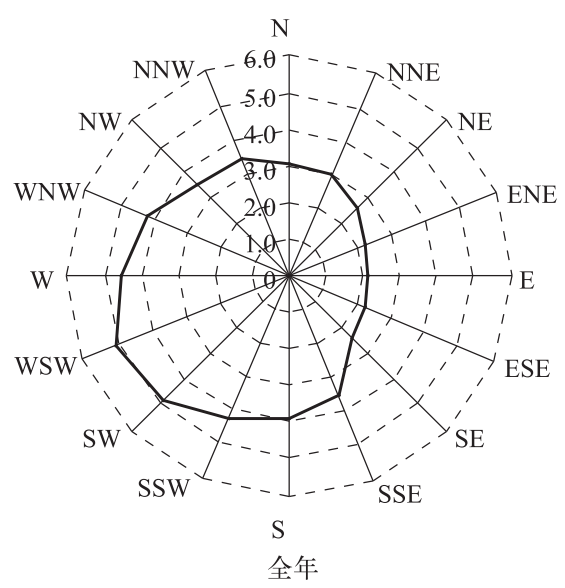

图 4 多伦县近 30 年全年风速玫瑰图

Fig.4 The figure of annual wind speed rose of Duolun County in recent 30 years

受降雨年内分配不均的影响, TP 湿沉降通量年内变异特征十分明显, TP 湿沉降通量最高值出现在降雨 量较大的 8 月, 为 $28.88 \mathrm{~kg} /\left(\mathrm{km}^{2} \cdot\right.$ 月) (图 2), 是年平均 TP 湿沉降通量 $8.77 \mathrm{~kg} /\left(\mathrm{km}^{2} \cdot\right.$ 月) 的 3.3 倍.

根据大气 TP 干、湿沉降通量统计结果, 确定各月大气 $\mathrm{TP}$ 干、湿沉降通量比例关系, 绘制大气 TP 干、湿 沉降通量比例月变化曲线. 由图 5 可见,2014 年 1-6月干沉降远大于湿沉降, TP 干沉降通量占总沉降通量 的 $55.15 \% \sim 97.92 \% .1-6$ 月库区降水量小, 月降水日数为 $11 \mathrm{~d}$ 以内, 干旱少雨, 大风天气居多, 因此大气 TP 沉降以干沉降为主. 7-9 月湿沉降明显大于干沉降. 7-9 月进人了一年中的多雨季节, 月降水日数为 12 $14 \mathrm{~d}$, 且降水不连续, 降雨短暂结束后, 受大风天气的影响, 空气中的附着含磷营养盐的飘尘、粉尘浓度开始 恢复, 伴随着降水强度的增大, 水库大气 TP 沉降以湿降尘为主, TP 湿沉降通量占总沉降通量的 $63.02 \%$ $76.28 \% .10-12$ 月降水量明显减少, 月降水日数少于 $5 \mathrm{~d}$, 受西伯利亚寒流的影响, 大风天气明显增多, 大气 TP 沉降以干沉降为主. 2014 年大河口水库全年 TP 沉降以干沉降为主, TP 月平均干、湿沉降通量分别占总 
沉降通量的 $60.79 \%$ 和 $39.21 \%$, TP 月平均干沉降通量占总沉降通量的比例是湿沉降通量占总沉降通量比例 的 1.55 倍, 这显然与翟水晶等对我国南部太湖梅梁湾地区研究得到的 TP 平均干沉降通量占总沉降通量为 $51.3 \%$ 、湿沉降占 $48.7 \%$ 的结论有较大差异 ${ }^{[12]}$. 这可能与我国南北部气候差异显著有关, 北部地区干旱少 雨,植被覆盖度低,地表沙土裸露,春、秋季节风沙大,易产生沙尘暴, 冬季采暖燃烧矿物燃料,含磷矿物质的 沙尘、粉尘等造成研究区 TP 干沉降通量较高, 而南方地区气候湿润, 年内降雨量大, 降雨连续而集中, 受雨 水冲刷将大气中吸附磷物质的灰尘降落至地面或水域, 引起南方地区出现湿沉降通量明显高于干沉降通量 的现象 ${ }^{[15,23-24]}$.

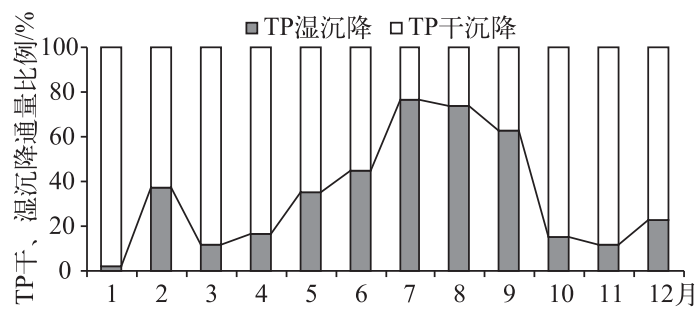

图 5 大河口水库大气 TP 干、湿沉降通量比例

Fig.5 Monthly variation of dry and wet deposition flux proportions of atmospheric TP in Dahekou Reservoir area

\section{3 大气 TP 湿沉降通量与降水量的关系}

大气降尘中 TP 湿沉降通量与年内各月降水量的分配密切相关. 大河口水库大气 TP 湿沉降通量随时间 变化规律与降水量各月分配规律基本相吻合,二者呈显著线性正相关关系 $\left(R^{2}=0.8119\right)$. 最低值均出现在降 水量最小的 1 月,最高值均出现在降水量较大的 8 月 (图 6). 主要由于 1 月受西伯利亚寒流的影响为全年降 水量最小月,随着季节的交换更替, 气温升高, 8 月雨季降水量骤增, 而水库周边农牧民以畜牧业和种植业为 主, 8 月农业活动最强,马铃薯、玉米等农作物处于快速生长期,农田施肥量剧增,农田化肥中的含磷营养盐 随高温挥发和扬尘进人大气环境,最终通过降雨冲刷降落至地面或水域.

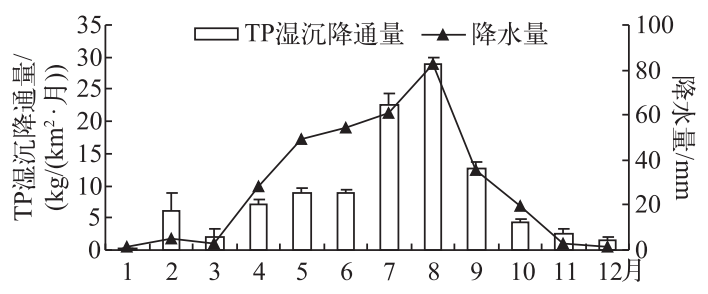

图 6 大河口水库大气 TP 月湿沉降通量与降水量的关系

Fig.6 Relationship between monthly wet deposition flux of TP and monthly precipitation in Dahekou Reservoir area

\section{4 大气 TP 干、湿沉降入库污染负荷分析}

采用 2014 年 1-12 月大河口水库 TP 总沉降通量, 结合对水库各月水面面积统计, 可估算通过大气沉 降人库的 TP 污染负荷量 (表 2).

表 22014 年大气 TP 沉降输人大河口水库污染负荷量的估算结果

Tab.2 Estimated results of TP pollution load of Dahekou Reservoir from atmospheric deposition in 2014

\begin{tabular}{lccccccccccccc}
\hline 指标 & 1月 & 2 月 & 3 月 & 4 月 & 5 月 & 6 月 & 7 月 & 8 月 & 9 月 & 10 月 & 11 月 & 12 月 & 全年 \\
\hline 沉降通量 $/\left(\mathrm{kg} /\left(\mathrm{km}^{2}\right.\right.$-月 $\left.)\right)$ & 12.27 & 9.26 & 16.17 & 42.80 & 25.19 & 19.51 & 29.59 & 39.11 & 29.10 & 40.02 & 20.46 & 6.32 & - \\
面积 $/ \mathrm{km}^{2}$ & 2.33 & 2.52 & 2.36 & 2.58 & 2.66 & 2.73 & 2.16 & 2.41 & 2.89 & 2.33 & 2.31 & 2.40 & - \\
TP 负荷量 $/ \mathrm{t}$ & 0.029 & 0.023 & 0.038 & 0.111 & 0.067 & 0.053 & 0.064 & 0.094 & 0.084 & 0.093 & 0.047 & 0.015 & 0.719 \\
\hline
\end{tabular}


为了与河流人库 TP 污染负荷量进行对比, 明确大气沉降对水库的 TP 污染贡献, 根据 2014 年各月吐力 根河、㴒河人库断面的 TP 浓度监测值, 结合同期大河口水库管理站提供的两河人库径流资料 (考虑人库河 流流量具有瞬时性, 本次估算采用每月每日流量数据的平均值统计), 按公式 (3) 估算河流输人水库的 TP 污 染负荷量, 结果见表 3.

表 32014 年河流输人大河口水库 TP 污染负荷量的估算结果

Tab.3 Estimation results of TP pollution loads of Dahekou Reservoir from runoff in 2014

\begin{tabular}{|c|c|c|c|c|c|c|c|c|}
\hline \multirow[b]{2}{*}{ 月份 } & \multirow{2}{*}{$\begin{array}{c}\text { 时间/ } \\
\mathrm{d}\end{array}$} & \multicolumn{3}{|c|}{ 㴒河 } & \multicolumn{3}{|c|}{ 吐力根河 } & \multirow{2}{*}{$\begin{array}{l}\text { 两河人库 TP } \\
\text { 总负荷量/t }\end{array}$} \\
\hline & & $\begin{array}{l}\text { 流量/ } \\
\left(\mathrm{m}^{3} / \mathrm{s}\right)\end{array}$ & $\begin{array}{c}\text { 人库 } \mathrm{TP} \text { 浓度/ } \\
(\mathrm{mg} / \mathrm{L})\end{array}$ & $\begin{array}{c}\mathrm{TP} \text { 负荷量/ } \\
\mathrm{t}\end{array}$ & $\begin{array}{l}\text { 流量/ } \\
\left(\mathrm{m}^{3} / \mathrm{s}\right)\end{array}$ & $\begin{array}{c}\text { 人库 TP 浓度/ } \\
(\mathrm{mg} / \mathrm{L})\end{array}$ & $\begin{array}{c}\text { TP 负荷量/ } \\
\mathrm{t}\end{array}$ & \\
\hline 1 月 & 31 & 0.055 & 0.19 & 0.028 & 0.029 & 0.15 & 0.012 & 0.040 \\
\hline 2 月 & 28 & 0.050 & 0.16 & 0.019 & 0.027 & 0.13 & 0.008 & 0.028 \\
\hline 3 月 & 31 & 0.071 & 0.14 & 0.027 & 0.031 & 0.15 & 0.012 & 0.039 \\
\hline 4 月 & 30 & 0.103 & 0.25 & 0.067 & 0.034 & 0.22 & 0.019 & 0.086 \\
\hline 5 月 & 31 & 0.126 & 0.32 & 0.108 & 0.038 & 0.30 & 0.031 & 0.139 \\
\hline 6 月 & 30 & 0.108 & 0.30 & 0.084 & 0.037 & 0.28 & 0.027 & 0.111 \\
\hline 7月 & 31 & 0.118 & 0.29 & 0.092 & 0.052 & 0.25 & 0.035 & 0.126 \\
\hline 8 月 & 31 & 0.166 & 0.62 & 0.276 & 0.047 & 0.44 & 0.055 & 0.331 \\
\hline 9 月 & 30 & 0.181 & 0.53 & 0.249 & 0.054 & 0.39 & 0.055 & 0.303 \\
\hline 10 月 & 31 & 0.183 & 0.14 & 0.069 & 0.051 & 0.13 & 0.018 & 0.086 \\
\hline 11 月 & 30 & 0.101 & 0.18 & 0.047 & 0.034 & 0.16 & 0.014 & 0.061 \\
\hline 12 月 & 31 & 0.067 & 0.22 & 0.039 & 0.031 & 0.18 & 0.015 & 0.054 \\
\hline 合计 & & & & 1.104 & & & 0.301 & 1.405 \\
\hline
\end{tabular}

由表 2 和表 3 可见, 2014 年通过大气沉降输人大河口水库的 TP 污染负荷量为 0.719 t. 同年两河人库 TP 负荷总量为 $1.405 \mathrm{t}$, 其中滦河人库 TP 负荷量为 $1.104 \mathrm{t}$, 吐力根河人库 TP 负荷量为 $0.301 \mathrm{t}$. 大气 TP 沉降 污染负荷占河流输人水库 TP 污染负荷的 51.17\%. 由此可见, 大气 TP 沉降对水库的贡献率甚至比河流径流 输人还高, 这与杨龙元等 ${ }^{[10]}$ 研究得到的 2012-2013 年我国南部地区太湖水面接受大气 TP 沉降污染占环湖 河道输人量的比值为 $46.2 \%$ 的研究结论有所不同, 这主要与大河口位于我国北方地区, 降雨偏少, 干沉降是 大气输人 $\mathrm{TP}$ 的主要方式,且与人库河流㴒河上游淀粉厂排污和煤化工厂排污废水 TP 含量有直接关系; 另 一方面河流径流水体中磷浓度较低, 而大气降尘中携带的含磷矿物质的输人成为水库磷污染物的主要途径.

为了进一步对比大气和河流两种途径对水库磷污染的贡献, 并了解各自的变化规律, 根据表 2 和表 3 , 得到两种途径的 TP 贡献率 (图 7). 大气沉降人库 TP 污染负荷量对水库 TP 总负荷量的影响较大, 尤其是春 季 (3-5 月), 沙尘暴天气频发, 通过大气沉降途径对水库 TP 污染负荷量的贡献率达到了 $32.60 \% \sim 56.31 \%$, 是水库磷营养盐的主要输人途径, 磷作为水体富营养化的限制因子, 大气沉降 TP 输人对水库藻类的发育起 到了至关重要的作用, 也是夏、秋季节水库出现重富营养化的直接诱因. 夏季 ( $6-8$ 月), 迎来了降雨高峰 期, 人库河流进人汛期, 丰水期水库地表径流人库 TP 的贡献率达到了 $66.40 \% \sim 77.88 \%$, 在藻类大量繁殖的 夏季, 地表径流携带的磷营养盐会促使藻类大量生长, 加剧了大河口水体的富营养程度. 秋季 (9-11月), 受季风气候的影响, 风沙扬尘天气增多, 降雨量开始减少, 河流输人水库 TP 贡献率为 $48.15 \%$ 78.31\%, 同期 大气沉降人库 TP 贡献率为 $21.69 \%$ 51.85\%, 河流输人和大气沉降共同成为水体 TP 营养盐输人的主要途 径. 冬季(12-2 月), 气温降低, 水库处于冰封期, 由于水库冰面的阻隔作用, 大气沉降 TP 人库污染负荷量 和对水库 TP 贡献率比重虽然较大, 但不会对冬季水库 TP 浓度产生直接影响, 河流径流成为影响和控制水 库磷营养盐含量的主要途径.

\section{3 结论}

1) 受我国北方地区春季沙源起尘, 秋季农田施肥及沙源区典型气候特征的影响, 2014 年大河口水库 TP 


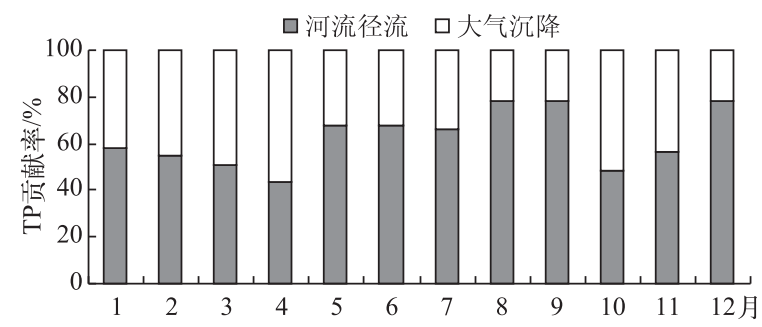

图 7 大河口水库两种途径 $\mathrm{TP}$ 贡献率的月变化规律

Fig.7 Monthly variation of contribution rates of two phosphorus loading paths in Dahekou Reservoir

月干沉降通量变化趋势呈双峰型特征, 表现为春、秋两季 TP 月干沉降通量高于夏、冬季. 大河口水库全年 $\mathrm{TP}$ 沉降以干沉降为主,干、湿沉降通量分别占总沉降通量的 $60.79 \%$ 和 $39.21 \%$. TP 湿沉降通量与降水量变 化关系紧密,二者呈显著线性正相关.

2) 受季风和年内降水分配极不均匀等气候条件的影响, 大河口水库 TP 总沉降通量变化范围为 6.32 $42.80 \mathrm{~kg} /\left(\mathrm{km}^{2} \cdot\right.$ 月 $)$, 平均值为 $22.96 \mathrm{~kg} /\left(\mathrm{km}^{2} \cdot\right.$ 月 $)$. 全年各月 $\mathrm{TP}$ 干沉降通量变异系数为 0.60 , 湿沉降通量 变异系数为 $1.00 . \mathrm{TP}$ 月干沉降通量值年内各月相对变异小, 而月湿沉降通量受年内各月降雨分配极不均匀 的影响,变异特征显著.

3) 与我国南方湖泊水库磷沉降污染特征不同, 北方沙源区水库大气干、湿沉降成为输人水库总磷来源 的主要途径, 大气 TP 沉降人库污染负荷占同期河流输人水库 TP 污染负荷的 $51.17 \%$, 比河流磷营养盐输人 对水库的污染贡献率略高, 对水库富营养化的贡献及带来的水环境问题不容小视.

\section{4 参考文献}

[ 1 ] Chang Yunhua, Liu Xuejun, Li Kaihui et al. Research progress in atmospheric nitrogen deposition. Arid Zone Research, 2012, 29(6) : 972-979. [ 常运华, 刘学军, 李凯辉等. 大气氮沉降研究进展. 干旱区研究, 2012, 29(6) :972-979.]

[ 2 ] Duce RA. The impact of atmospheric nitrogen, phosphorus and iron species on marine biological productivity, In:Buat-Menard P ed. The role of air-sea exchange in geochemical cycling. D. Reidel, Norwell, MASS, 1986: 497-529.

[ 3 ] Zhai SJ, Yang LY, Hu WP. Observations of atmospheric nitrogen and phosphorus deposition during the period of algal bloom formation in northern Lake Taihu, China. Environmental Management, 2009, (44) : 542-551.

[ 4 ] Migon C, Sandroni V, Bthoux JP. Atmospheric input of anthropogenic phosphorus to the northwest Mediterranean during the oligotrophic season. Marine Environmental Research, 2001, 52(5) : 413-426.

[ 5 ] Herut B, Krom MD, Pan G et al. Atmospheric input of nitrogen and phosphorus to the southeast mediterranean: Source, fluxes, and possible impact. Limnology and Oceanography, 1999, 44(7): 1681-1692.

[ 6 ] Morales JA, Albornoz A, Socorro E. An estimation of nitrogen and phosphorus loading by wet deposition over lake Maracaibo, Venezuela. Water, Air, Soil Pollut, 2001, 128: 207-221.

[ 7 ] Tamatamah RA, Hecky RE, Duthie HC. The atmospheric deposition of phosphorus in Lake Victoria(East Africa). Biogeochemistry, 2005, 73(2): 325-344.

[ 8 ] Markaki Z, Oikonomou K, Kouvarakis G et al. Atmospheric deposition of inorganic phosphorus in the Levantine Basin, eastern Mediterranean: Spatial and temporal variability and its role in seawater productivity. Limnology and Oceanography, $2003,48(4)$ : 1557-1568.

[ 9 ] Vicars WC, Siekman JO, Ziemannn PJ. Atmospheric phosphorus deposition at a montane site: Size, distribution, effects of wild fire and ecological implication. Atmospheric Environment, 2010, 44: 2813-2810.

[10] Yang Longyuan, Qin Boqiang, Hu Weiping. The atmospheric deposition of nitrogen and phosphorus nutrients in Taihu Lake. Oceanologia et Limnologia Sinica, 2007, 38(2): 104-110. [杨龙元, 秦伯强, 胡维平. 太湖大气氮、磷营养元 素干湿沉降率研究. 海洋与湖泊, 2007, 38(2) : 104-110.]

[11] Yu Hui, Zhang Lulu, Li Huanli. Atmospheric wet deposition characteristics of nitrogen and phosphorus nutrients in Taihu Lake and contribution to the Lake. Research of Environmental Sciences, 2011, 24(11): 1210-1219. [余辉, 张璐璐, 李 
煥利. 太湖氮磷营养盐大气湿沉降特征及人湖贡献率. 环境科学研究, 2011, 24(11) : 1210-1219.]

[12] Zhai Shuijing, Yang Longyuan, Hu Weiping et al. Atmospheric nitrogen and phosphorus deposition during optimal algal growth period in northern Lake Taihu. Environment Pollution and Control, 2009, 31(4) : 5-10. [翟水晶, 杨龙元, 胡维 平等. 太湖北部藻类生长旺盛期大气氮、磷沉降特征. 环境污染与防治, 2009, 31(4) : 5-10.]

[13] Chen Zhongying, Li Kaiming, Lin Wenshi. Atmospheric dry and wet deposition of nitrogen and phosphorus in the Pearl River Estuary. Environmental Pollution and Control, 2010, 32(11): 53-57. [ 陈中颖, 李开明, 林文实. 珠江口大气氮 磷干湿沉降通量及其污染特征. 环境污染与防治, 2010, 32(11): 53-57.]

[14] Lu Junping, Ma Tailing, Zhang Xiaojing et al. Reservoir pollution by dry and wet deposition of atmospheric nitrogen in typical sand area. Journal of Agro-Environment Science, 2015, 34(12): 2357-2363. [卢俊平, 马太玲, 张晓晶等. 典型沙 源区水库大气磷干、湿沉降污染特征研究. 农业环境科学学报, 2015, 34(12) : 2357-2363.]

[15] Lu Junping. Study on the mechanism of nitrogen and phosphorus pollution of reservoir in sand source areas based on watersediment-dust three interfaces[Dissertation]. Hohhot: Inner Mongolia Agricultural University, 2015: 6. [卢俊平. 基于 水-底泥-降尘三相界面下沙源区水库氮磷污染机理研究 [ 学位论文]. 呼和浩特: 内蒙古农业大学, 2015: 6. ]

[16] Song Huanhuan, Jiang Chunming, Yu Wantai et al. Basic features and monitoring methodologies of atmospheric nitrogen deposition. Chinese Journal of Applied Ecology, 2014, 25(2) : 599-607. [ 宋欢欢, 姜春明, 宇万太等. 大气氮沉降的 基本特征与监测方法. 应用生态学报, 2014, 25(2) : 599-607.]

[17] "Monitoring and analysis method of water and wastewater" editorial board of State Environmental Protection Administration of China ed. Monitoring and analysis method of water and wastewater: Fourth Edition. Beijing: China Environmental Science Press, 2002. [ 国家环境保护总局《水和废水监测分析方法》编委会. 水和废水监测分析方法: 第 4 版. 北京: 中国环境科学出版社, 2002.]

[18] Li Taiqian, Jiao Feng, Zheng Yi. Atmospheric nitrogen and phosphorus deposition in spring and summer in Beili Lake in Hangzhou. Environmental Science and Technology, 2010, 23(6): 66-75. [李太谦, 焦锋, 郑炏. 杭州北里湖春、夏季大 气氮、磷沉降研究. 环境科技, $2010,23(6): 66-75$.

[19] Jin Xiangcan, Tu Qingying eds. Lake eutrophication investigation and specification. Beijing: Environmental Science Press of China, 1990. [ 金相灿, 屠清瑛. 湖泊与营养化调查规范. 北京: 中国环境科学出版社, 1990.]

[20] Graham WF, Duce RA. Atmospheric pathways of the phosphorus cycle. Geochimica et Cosmochimica Acta, 1979, 43(8) : 1195-1208.

[21] Cole JJ, Caraco NF, Likens GE. Short-range atmospheric transport: A significant source of phosphorus to an oligotrophic lake. Limnology and Oceanography, 1990, 35(6) : 1230-1237.

[22] Gu Dongmei, Deng Kaiyu, Li Taiqian et al. Study on the atmospheric deposition of nitrogen and phosphorus in Beili Lake of Hangzhou. Safety and Environmental Engineering, 2013, 20(1) : 36-40. [顾冬梅, 邓开宇, 李太谦等. 杭州北里湖 大气沉降研究. 安全与环境工程, 2013, 20(1) : 36-40.]

[23] Luo Jun, Wang Xiaorong, Yang Hong et al. Concentrations of aerosol phosphorus in spring, 2003 above Meiliang Bay, Lake Taihu. J Lake Sci, 2005, 17(2) : 151-156. DOI: 10.18307/2005.0210. [罗军, 王晓蓉, 杨翃等. 太湖梅梁湾上 空颗粒态磷浓度 2003 年春季的变化. 湖泊科学, 2005, 17(2) : 151-156. ]

[24] Liu Changling, Chen Hongtao, Ren Hongbo et al. Nutrient elements in wet deposition( precipitation) from the Yellow Sea and the East China Sea regions. Marine Environmental Science, 2003, 22(3): 26-30. [刘昌岭, 陈洪涛, 任宏波等. 黄 海及东海海域大气湿沉降(降水) 中的营养元素. 海洋环境科学, 2003, 22(3) : 26-30.] 